\title{
Paying Fare and Playing Fair on a Commuter Bus: A Mind Genomics Cartography of Topics Appropriate for Ethics
}

\author{
Howard Moskowitz ${ }^{1 *}$, Arthur Kover ${ }^{2}$, Pnina Deitel ${ }^{3}$, Hollis Belger ${ }^{4}$, Konstantin Vuk Savicevich ${ }^{5}$ and Attila Gere $^{6}$ \\ ${ }^{1}$ World Institute of Competitive Excellence, LLC, NY, USA \\ ${ }^{2}$ Independent Researcher, USA \\ ${ }^{3}$ The Open University, Jerusalem, Israel \\ ${ }^{4}$ Independent Researcher, USA \\ ${ }^{5}$ Tino Space Ltd., Belgrade, Serbia \\ ${ }^{6}$ Hungarian University of Agriculture and Life Sciences, Budapest, Hungary
}

*Corresponding author: Howard Moskowitz, World Institute of Competitive Excellence, LLC, NY, USA

Received: February 26, 2021; Accepted: March 08, 2021; Published: March 10, 2021

\begin{abstract}
Respondents evaluate combinations of short phrases, rating each combination as either being relevant to ethics, or not relevant to ethics. The topic was the daily behavior of a local or a commuter bus, ranging from the nature of the bus ride, what was the person taking the ride either doing or feeling, how the fare was given to the bus driver, and what happened afterwards. The deconstruction of the responses revealed two clearly different groups of people having different 'mind-sets' about what ethics deals with in this ordinary, quotidian situation. One group felt that ethics pertains to the nature of the daily activity, the nature of the bus ride, and the feeling of the person described. The other mind-set felt that ethics pertained to the nature of how the rider handled the payment of a fare. The Mind Genomics approach provides a deep understanding of the nature of ethics, casting light on the nature of how one thinks about the topic of ethics, rather than immediately jumping into the ethical issues themselves.
\end{abstract}

\section{Introduction}

Traditionally, ethics have been studied in the context of problems which are often puzzling. These problems, like 'who should one kill' in a specific situation when faced with a two-alternative situation, are designed to make people think about the issues underlying ethics. The problems are often deep, have no clear answer, and are striking, unusual in their nature. The problems force deep thinking. It is no wonder that many of these are popular 'ignition devices' for a course on ethics. Mind Genomics is an emerging behavioral science, which deals in the simplest format with the way people make decisions in situations with different aspects. The underlying principle for Mind Genomics is that by mixing different features of a situation, creating alternative 'realities', and observing the decision a person makes, one can identify the criteria used by the person.

Traditional uses of Mind Genomics begun with issues involving economics, usually issues involving consumer purchases [1-3]. The economics aspect moves from individual micro-economic decisions encountered in marketing, and onto more complex situations such as issues of public policy and what to do [4]. Over the years, the original uses of the approaches called conjoint measurement [5] evolved from the study of issues regarding finances to issues regarding social wellbeing [6] and even into law [7].

\section{Mind Genomics Meets 'Ethics'}

The study reported here, a 'cartography' in the language of Mind Genomics, resulted from a discussion by author HRM with a group of students in Israel. The question was 'how do we know what is ethical in the world of everyday?' The question was framed as an inquiry into how one goes about establishing ethics in the world of the everyday experience. People know that it is unethical to murder, and so forth. There is the sense of ethics, whether that sense is innate from natural law, or emerging from convention, and internalized through education to become normative, both in action and in thought. The issue was not those topics, but rather the nature of right and wrong in the small actions of the everyday, actions where one might say are minor 'peccadillos' rather than ethical issues [8,9]. In an excellent summary article 'ethical feelings' for behavior, including the 'ordinary can be introduced by the simple set of paragraphs:

\section{So, What is Ethics?}

Ethics is the manner by which humans regulate individual behavior in civilized society. One might say that humans regulate behavior by laws, which is true. But laws cannot apply in every instance, and all the time. So, ethics is how we train people to behave, or teach them how they ought to behave, even if no laws apply in some circumstance (source: https://www.oocities.org/athens/acropolis/1628/A53ethic. 
htm). A deeper look into the world of ethics and how it could involve Mind Genomics would move from a simple research paper to books. The literature on ethics is vast, with roots stretching back to antiquity. A simple search in Google Scholar for 'What is relevant for ethics?' generated 2.95 million 'hits.' The need to know the difference between 'right' and 'wrong' remains an important issue, and the topic of inquiries reaching into academia and the teaching of ethics [10]. The need has been stated by philosophers, but manifests itself everywhere, from daily life to the machinations and strategies of corporations projecting themselves in a favorable light [11].

Mind Genomics as a science deals with studying and understanding human responses to outside stimuli, whereas it focuses on measuring deep structure of thinking, subconscious mechanisms that go on in the mind. Since we deal with the mind processes that originate on a cellular level, a direct relationship with the genome indicates that there is genetic participation in determining a response. Being a sort of an antenna, on a molecular level DNA acts both as a receiver of information and initiator of a response [12]. Therefore, when we apply Mind Genomics to research the topic of ethics, we gain insight to the inner workings of how we differ from one another and what we perceive as relevant to ethics. The study shows two distinct mindsets that differ in the way they respond to the sixteen elements, which shall be considered as sixteen commuter bus riding situations. The beauty of this science is that it enables us to study deep mind processes by creating a simple matrix and combing textual elements.

\section{Investigating Some 'Ethics' Aspects of an Everyday Behavior-paying the Fare on a Bus}

We demonstrate the application of Mind Genomics cartography to the simple problem of behavior on a commuter bus, and the issue of where the incident takes place, the payment situation, and the response of the driver, and finally who the person is. The underlying notion is to look at the nature of the behavior, and to decide whether the specific behavior should be a topic for ethics or not. The results reveal a strategy by which to understand the ethics of the every-day, where the behavior is the quotidian, almost automatic behavior which only occasionally involves what we would call 'ethics.

The focus of the Mind Genomics cartography is the nature of what a respondent considers to be in the realm of 'ethics', and conversely not in the realm of 'ethics.' In contrast to the traditional studies of ethics, which deal with general problems, Mind Genomics deals at the level of the mundane, granular, everyday experience. When the topic is ethics, the Mind Genomics approach is to present vignettes, combinations which describe different facets of everyday behavior, instruct respondents to read these vignettes, rate them, and from the data thus obtained, understand the topic almost from the bottom up. Applying Mind Genomics to ethics, and following the foregoing strategy, means that the researcher defines a topic (ethics), creates four questions (aka 'silos'), and four answers to each question (aka as 'elements.). The topic is ethics, the questions pertain to aspects of behavior on a commuter bus, and then different specifics of each aspect of behavior.

The important things to note concern the nature of the experiment. When we think of a commuter bus, we may think of ethics, but anything having to do with ethics is probably at the low end of importance. The issues involving what is in the realm of ethics for the mundane commuter trip are certainly far from dramatic, and perhaps require a stretch of imagination to link these behaviors we hardly notice to a topic so essentially human as ethics. Nonetheless, it is precisely the contribution of Mind Genomics to ethics, when the study pulls out ethical issues from the ordinariness of the situation, the lack of drama, and the difficulty of finding a link. We deal with the topic of the commuter bus, following the Mind Genomics process, as illustrated below:

\section{The Mind Genomics Process}

\section{Step 1: Define the Topic, and the Raw Materials}

This first step sounds easy, and in fact it begins with simply the statement of a topic. The topic must be reasonable circumscribed, limited so that it can be further investigated using specific statements.

The raw materials comprise four questions, each of which is answered by four different statements, phrases presented in the declarative form. Table 1 shows an example of the four questions, and the four answers for each question. It is important to keep in mind that the Mind Genomics process is rapid, inexpensive, and iterative, so that one need not be 'correct' at the start. Thus, the questions and answers in Table 1 can always be modified, improved, and resubmitted to the Mind Genomics process. There is no need to be 'right' on the first or indeed any iteration.

\section{Step 2: Combine the Answers into Vignettes Using an Experimental Design}

Mind Genomics works by presenting combinations of answers (elements) in a simple format, a set of elements and a rating scale. The respondent reads the introduction to the study, reads the combination of elements (the vignette), and rates the combination on the defined

Table 1: Raw materials (four questions, and four answers for each question).

\begin{tabular}{|l|c|}
\hline & Question A: what is the act? \\
\hline A1 & Getting on to a local bus in your neighborhood \\
\hline A2 & Getting on to a shared taxi in your neighborhood \\
\hline A3 & Getting on to a return bus from the city to your suburb \\
\hline A4 & Getting into a shared taxi from city to your suburb \\
\hline & Question B: How do you pay? \\
\hline B1 & You give in a fixed amount that may be less and say that's all I have \\
\hline B2 & You negotiate the price \\
\hline B3 & You give a deliberately higher amount and play dumb \\
\hline B4 & The money is taken, and correct change given \\
\hline C1 & The money is taken, and you pay less than you should \\
\hline C2 & They forget to take your money and you say nothing \\
\hline C3 & They forget to take your money and you remind them \\
\hline C4 & You are with your young child or grandchild \\
\hline it's the weekend and your happy to see your family \\
\hline D1 & You have been very sick and coming from hospital \\
\hline D2 & You feel tired from a long day \\
\hline D3 & D4 What are the circumstances? \\
\hline D4 & Yuesponse? \\
\hline
\end{tabular}


scale. Here the scale is a 9-point scale, anchored at the top (ethical) and at the bottom (non-ethical).

Most consumer research asks the respondent to rate one element or answer at a time, in order to maintain focus on the element. The practice of Mind Genomics is the opposite, namely, to simulate reallife and to prevent 'gaming the system' by having the respondent think of an appropriate answer for each element. By presenting combinations of vignettes, the combinations comprising 2-4 elements, Mind Genomics forces the respondent to sift through the vignette, doing so virtually automatically, without dee thinking, and without the ability to 'game the system' by providing the 'right' answer.

The experimental design itself comprises 24 combinations, vignettes. Each element from the set of 16 appears five times in the vignettes. A vignette can comprise at most one element from a question, viz., one answer for a question, ensuring that the vignette does not feature two different and possibly mutually contradictory ideas. The topic of experimental design in research has been dealt with extensively in various books. A good review is presented by [13]. The actual interview comprised a short introduction about age, gender, and a third question dealing attitude towards the law:

What do you consider yourself to be, given the following choices:

$1=$ Most of the time obey the rules rigidly,

$2=$ Don't complain if you get an advantage and don't hurt anyone,

$3=5$ Pragmatic honest but not stupid,

$4=$ Not applicable.

The self-profiling questionnaire followed by an introduction to the topic, and 24 vignettes. The introduction to the topic appeared on every vignette, at the top, with the respondent reading the vignette as a single 'thought'. Here are some common situations with transportation. Each is a vignette of a common situation. Please read it and rate the degree of ethical behavior described in the whole vignette. Let $1=$ totally unethical ... $9=$ totally ethical

\section{Step 3: Invite Respondents to Participate}

The interaction is an experiment but was positioned as a 'study' to make the respondents feel comfortable. The respondents were members of a large panel offered for use at a fee by Luc.id, a strategic partner of Mind Genomics Associates. The respondents were sent a link, began the study, and earned 'points' for their participation. The respondents did not know the purpose of the study nor could the respondents 'game' the study. The entire study took 3-5 minutes. The BimiLeap program recorded the specific combination, the rating on the 9-point scale, and the number of seconds from the appearance of the vignette on the screen to the rating. This latter time, recorded to the nearest tenth of a second, was called the response time.

\section{Step 4: Transform the Rating}

In the world of Mind Genomics, the objective is to relate the presence/absence of the elements (viz., the 16 answers) to the ratings assigned. Users of the Mind Genomics data prefer to view the results as 'no/yes', rather than as points along a graded Likert Scale, such the 9-points ethics scale. To make the results easy to understand, we transform the data twice, first to create a binary scale for 'Ethical' and then to create a binary scale for 'Not Ethical"

Transformation \#1: Ethics: Ratings of 7-9 $\rightarrow 100$, Ratings of 1-6 $\rightarrow 0$

Transformation \#2 Not Ethics: Rating of 1-3 $\rightarrow 100$, Ratings of 4 $-9 \rightarrow 0$

To each transformed number, whether 0 or 100 , we add a small random number $<10^{-5}$. This prophylactic measure ensures that when we use OLS (ordinary least-squares regression), even on the data of a single respondent, that there is guaranteed to be variation in the dependent variable. We also create a new variable, response time, which was defined above as the number of seconds, to the nearest tenth of second, elapsing between the presentation of the vignette and the response.

The data matrix emerging from the experiment and the transformation comprises the following:

1. Each row corresponds to a respondent and a vignette.

2. Each row corresponds to a particular variable, as follows:

a. Respondent Identification Number

b. Test order (1-24)

c. 16 columns, one column for each of the 16 elements or answers.

d. A cell for the 16 elements is ' 0 ' when the element does not appear in the vignette, and ' 1 ' when the element appears in the vignette. By design each vignette comprises 2-4 elements, at most one element or answer for a question. Thus majority of numbers in a row for the 16 columns is 0 , and the minority is 1 .

e. The actual rating originally assigned by the respondent.

f. The actual response time.

g. The Transformed value: For Ethics

h. The transformed value: Not for Ethics

i. A code showing the specific questions in the vignette. There are 11 different combinations of elements that can be made with 2-4 different sources or questions (Table 1). These range from $\mathrm{AB}$ (answer or element from question $\mathrm{A}$, answer from question $\mathrm{B}$ ), all the way to $\mathrm{ABCD}$ (one answer or element from questions $\mathrm{A}, \mathrm{B}, \mathrm{C}, \mathrm{D})$.

\section{Step 4: Analyze the Data to Uncover Three Mind-sets, and Create the Four Models (Total, Mind-sets)}

The matrix is now set up for OLS (ordinary least-squares) regression, both at the level of the individual respondent, and at the group level. OLS regression generates a simple equation of the form:

Rating or Transformed Rating $=\mathrm{k}_{0}+\mathrm{k}_{1} \mathrm{~A} 1+\mathrm{k}_{2} \mathrm{~A} 2 \ldots \mathrm{k}_{16} \mathrm{~A} 16$.

For the measurement of response time, the equation is almost the same, but without the additive constant, viz., Response Time $=\mathrm{k}_{1} \mathrm{~A} 1$ $+\mathrm{k}_{2} \mathrm{~A} 2 \ldots \mathrm{k}_{16} \mathrm{~A} 16$. 
The equation allows us to trace the contribution of each element to either the rating, the response time, or the transformed rating. The regression analyses, for Total Panel or for individuals, will be done primarily for the dependent variable of ethical (ratings of 1-6 transformed to 0 ; ratings of 7-9 transformed to 100). The additive constant is the estimated value of the dependent variable (e.g., binary transform of Not Ethical), in the absence of any elements. The additive constant is a strictly estimated parameter but gives a sense of the predisposition of the respondent to assign the rating, Thus, for the transformed variable 'Ethical', an additive constant of 48 means that $48 \%$ of the ratings are be $7-9$ in the absence of elements. The additive constant gauges the predisposition of a group to judge harshly (low additive constant for Ethical) or judge mildly (high additive constant for ethical).

The regression analysis can be done at the level of the individuals to general 103 individual equations. The vignettes for each respondent allow for the creation of a valid equation, because the vignettes were created by an experimental design, complete on an individualby-individual basis. The design was permuted to create different combinations, but the same mathematical structure was maintained, underlying the specific permutation for each respondent [14]. One can imagine now a matrix of 17 columns, an additive constant and 16 coefficients. The matrix comprises 103 rows, one per respondent. A separate statistical analysis called the cluster analysis [15] divides the 103 respondents into either two or three groups, based upon the dissimilarity of the patterns of 16 coefficients.

For this study, the clustering generated three different groups, called mindsets MSA, MSB, and MSC, respectively. We do not know the names of these mind-sets. We just know that respondents in the same mind-set show similar patterns of the 16 coefficients. (The additive constant is discarded). Mind-sets A and B were similar to each other, sharing a number of strong performing elements, and were thus combined into one new mind-set, MS1. Mind-set C became MS2. The final analysis creates three equations, one for Total Panel, and one model each for the two mind-sets. It is important to keep in mind that often mind-sets of interest must first emerge, be kept separate, and the remaining mind-sets recombined. Thus Mind-Set 2 did not emerge when two mind-sets were extracted. Mind-Set 2 emerged only when three mind-sets are extracted.

\section{Step 5: Post the Coefficients in a Way Which Allows the Mind-sets to Emerge}

Table 2 shows the positive coefficients of the Total Panel and of the two mind-sets. The table is sorted to show which elements perform very strongly (shaded). A coefficient of +8 or higher corresponds to ay strong performing element with an expected value for the coefficient around 2.0 or higher. The coefficients of 0 or lower are not shown because they add no insight.

The additive constant for the Total Panel is 48 , meaning that in the absence of any information, we expect $48 \%$ of the responses to be $7-9$, defined as 'Ethical' in the mind of the respondent. MS2 is slightly more generous, with $53 \%$ of the ratings $7-9$, whereas MS3 is less generous, with $40 \%$ of the ratings $7-9$. Beyond the additive constant, it is the pattern of coefficients which tells us the difference between groups in terms of what they feel to be 'Ethical'. MS1 feels that ethical behavior is the behavior of the ordinary, the routine activities of the every-day. Ethical behavior is what normal people do.

MS2 feels that ethical behavior is an interchange, a decision to do something. Ethical behavior has nothing to do with daily routine

Table 2: Models for Ethics (viz., involves ethics) for Total Panel and two final mind-sets)

\begin{tabular}{|c|c|c|c|c|}
\hline & Ethics (Ratings 7-9 $\rightarrow$ 100) & Total & MS1 & MS2 \\
\hline & Additive constant ('Ethical' in the absence of elements) & 48 & 53 & 40 \\
\hline & MS1 - Ethical is what you do regularly & & & \\
\hline A3 & Getting on to a return bus from the city to your suburb & & 10 & \\
\hline A1 & Getting on to a local bus in your neighborhood & & 10 & \\
\hline \multirow[t]{2}{*}{ A2 } & Getting on to a shared taxi in your neighborhood & 3 & 8 & \\
\hline & MS2 - Ethical is determined by how you behave in a situation of volitional gain and loss & & & \\
\hline B3 & You negotiate the price if you can & & & 23 \\
\hline B2 & You ask the price and pay it & & & 22 \\
\hline B4 & You give a deliberately higher amount and play dumb & & & 15 \\
\hline B1 & You give in a fixed amount that may be less and say that's all I have & & & 12 \\
\hline D3 & You have been very sick and coming from hospital & & & 8 \\
\hline \multirow[t]{2}{*}{ D2 } & it's the weekend and your happy to see your family & & & 8 \\
\hline & Elements which do not relate to ethics & & & \\
\hline D4 & You are with your young child or grandchild & & & 4 \\
\hline D1 & You feel tired from a long day & & & 3 \\
\hline $\mathrm{C} 2$ & The money is taken and you pay less than you should & 2 & 4 & \\
\hline $\mathrm{C} 1$ & The money is taken and correct change given & & 3 & \\
\hline $\mathrm{C} 4$ & They forget to take your money and you remind them & & 2 & \\
\hline A4 & Getting into a shared taxi from city to your suburb & & & \\
\hline $\mathrm{C} 3$ & They forget to take your money and you say nothing & & & \\
\hline
\end{tabular}


Table 3: Models for Not Ethics (viz., does not involve ethics) for Total Panel and two mind-sets.

\begin{tabular}{|c|c|c|c|c|}
\hline & Does Not Involve Ethics (Ratings 1-3 transformed to 100) & Total & MS1 & MS2 \\
\hline & Additive constant (Not ethical in the absence of elements) & 17 & 14 & 22 \\
\hline & MS1 -One situation does not involve ethics & & & \\
\hline \multirow[t]{2}{*}{ D2 } & It's the weekend and you're happy to see your family & 6 & 10 & \\
\hline & MS 2 - Going somewhere does not involve ethics & & & \\
\hline A3 & Getting on to a return bus from the city to your suburb & 4 & & 12 \\
\hline A4 & Getting into a shared taxi from city to your suburb & 4 & 1 & 11 \\
\hline A1 & Getting on to a local bus in your neighborhood & 4 & & 11 \\
\hline \multirow[t]{2}{*}{ A2 } & Getting on to a shared taxi in your neighborhood & & & 10 \\
\hline & Elements which may involve ethics & & & \\
\hline D4 & You are with your young child or grandchild & 4 & 4 & 4 \\
\hline $\mathrm{C} 3$ & They forget to take your money and you say nothing & 5 & 6 & 3 \\
\hline D1 & You feel tired from a long day & 3 & 4 & 2 \\
\hline D3 & You have been very sick and coming from hospital & 4 & 5 & 2 \\
\hline $\mathrm{C} 2$ & The money is taken and you pay less than you should & & & 2 \\
\hline $\mathrm{C} 1$ & The money is taken and correct change given & 1 & 1 & 1 \\
\hline $\mathrm{C} 4$ & They forget to take your money and you remind them & 2 & 3 & 1 \\
\hline B3 & You negotiate the price of you can & & 5 & \\
\hline B2 & You ask the price and pay it & & 5 & \\
\hline B1 & You give in a fixed amount that may be less and say that's all I have & & 3 & \\
\hline B4 & You give a deliberately higher amount and play dumb & & 3 & \\
\hline
\end{tabular}

behavior, but rather has to do with volitional behavior, where there are gain and loss involved.

We can now look at the same data and mind-sets, but from the viewpoint of what constitutes 'non ethical behavior.' Not ethical behavior may either be 'unethical behavior', or more likely behavior that has nothing to do with ethics. Mind-Set 1 may feel that D2 is the only element which does not relate to ethics. Mind-Set 2 may feel that going somewhere is something which does not involve ethics. Recall that for them, ethics were involved in volitional behavior with money.

The important thing here is that the respondents have a sense of what they feel 'involves ethics.' Table 3 shows that they have an equivalent and complementary feeling of what does involve ethics.

Step 6: Effect of Repeated Evaluations on Ratings

The permuted experimental design ensures that each respondent evaluates a unique set of vignettes. Thus, across the set of 103 respondents and 24 vignettes per respondent we have 2472 combinations. Often the issue is raised that during the evaluation the respondent may lose interest, and simply assign random numbers. If that is the case, we might see a decrease in the variation of average ratings as the respondent presses the same number to finish the task.

Figure 1 shows two sets of plots. The four left plots show the average response times, ratings, and transformed binary values for Mind-Set 1 , the group which felt that the 'everyday' actions involved ethics. The

\section{Ethics involve}

\section{MS1 (Everyday behavior)}
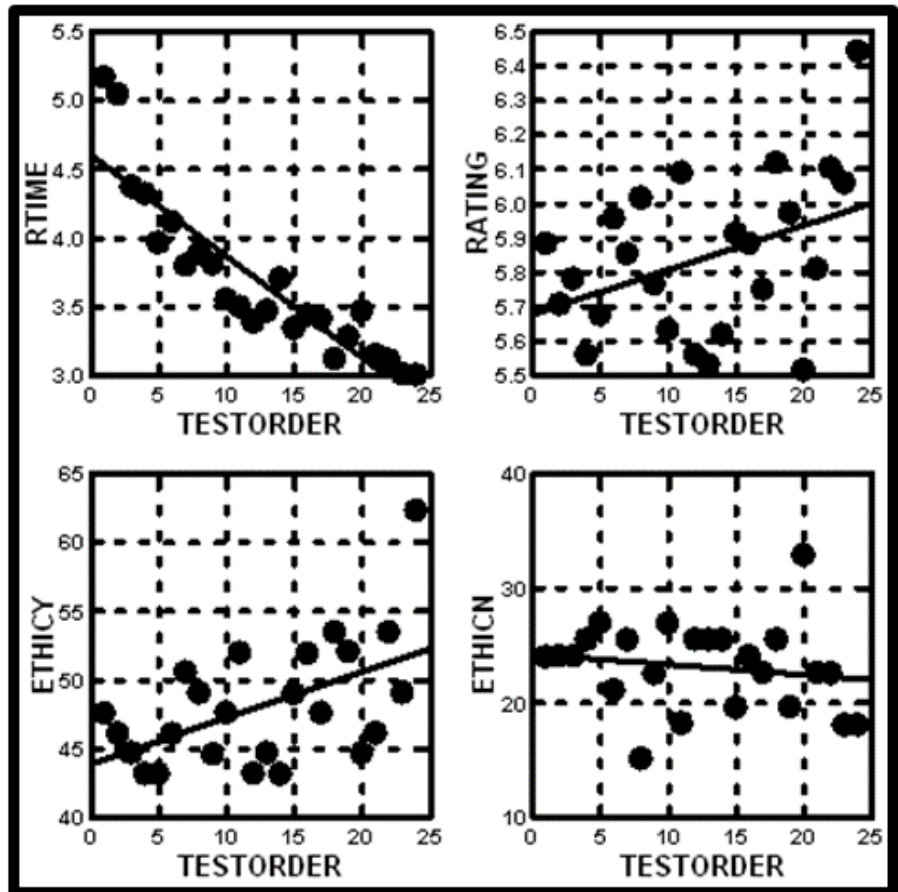

\section{MS2 (How you deal with money)}
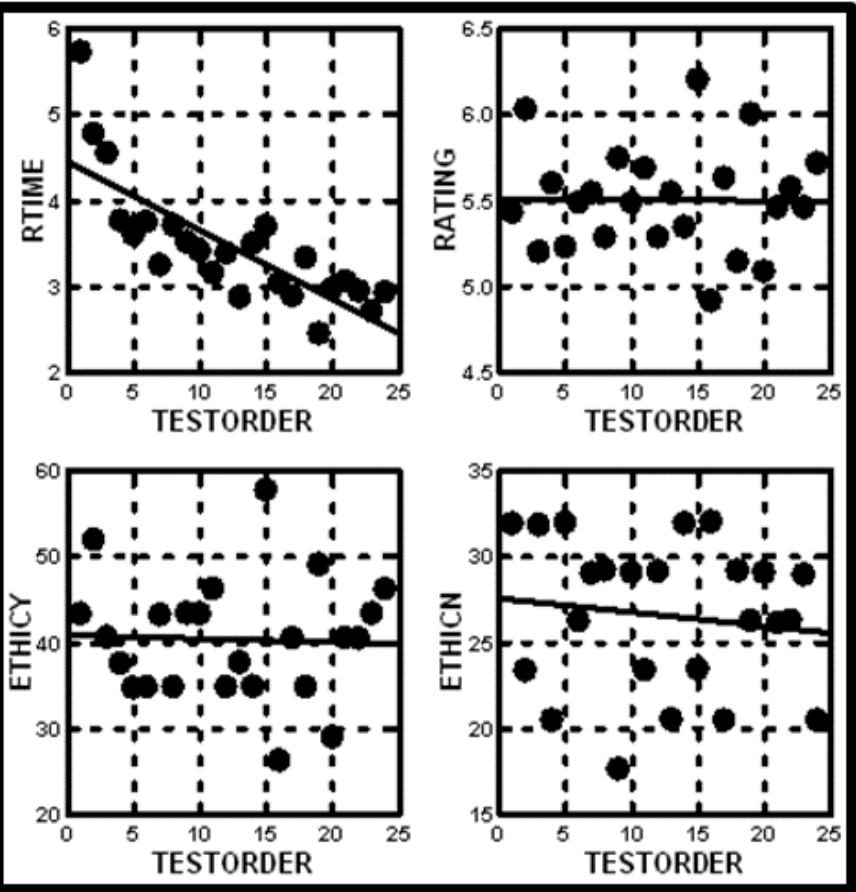

Figure 1: How the average response time, rating, and value for Ethical and Not Ethical change with repeated exposure in an experiment. Each point represents the average rating for all vignettes evaluated in the position. The left panel shows the patterns Mind-Set 1 . The right panel shows the pattern for Mind-Set 2 the more stringent mind-set. 
four right plots show the average response times and ratings for MindSet 2, which felt that ethics are involved in the volitional handling of money. In this study both mind-sets MS1 and MS2 show similar patterns of decreasing response times through the entire evaluation of 24 vignettes.

MS1 and MS2 differed in what they felt to be ethical. MS1 (ethics deals with the every-day) became more lenient as they proceeded, feeling more of the element were 'ethical' as they proceeded through the evaluation. In contrast, as the experiment proceeds, there is no effect on judgments of 'ethical' by MS2 (ethics deals with volitional situations with gain and loss).

\section{Interactions among Variables}

The data from the clustering suggests two mind-sets, MS1 focusing on ethics being relevant to the everyday activities, and MS2 focusing on ethics being relevant to the nature of financial transactions under a person's control. The final issue for this paper is to determine the degree to which the involvement of ethics with the everyday (Mind Set 1) or with financial transactions (Mind Set 2) can be intensified or in contrast, can be attenuated, by specific external factors. We have already identified the mind-sets by the pattern of their coefficients. It is the pattern which defined the mind-sets.

Recent efforts by author Moskowitz have shown that the strategy of permuted design permits a deeper understand of the mind of the respondent by revealing the effect of one element on another, socalled scenario analysis [1]. That is, through stratification of the data, and subsequent OLS statistics, on a stratum-by-stratum basis, one can quickly see how on type of element can influence how you feel about the involvement of a topic in ethics. Put in simpler terms, Mind Genomics allows us to answer questions such as: 'We know that you feel an everyday activity, such as A1, Getting on to a local bus in your neighborhood, is an elements where ethics is relevant. A new question is the degree to which other elements from other questions, such as $\mathrm{D}$ (what you are doing, how you are feeling) drive the involvement of ethics of element A1. That is, can one element affect the response to another element in the same vignette, or are the elements evaluated totally separately?

To answer the foregoing question, viz., interaction of pairs of elements, the analysis separates the full data set into a pair of datasets, each with five matching strata. The data are divided first by the mindset to which the respondent has been assigned. This division creates two databases, that will be analyzed separately, but in parallel. For each of the two databases one per mind-set, we create five strata, each stratum defined by the value of the element from silo or question $\mathrm{D}$ (who the respondent is, or how the respondent feels). There are five values of $\mathrm{D}(\mathrm{D}=0$, absent .... $\mathrm{D}-4)$. We then run five OLS regression, with the independent variables being A1-C4 (12 predictor, not 16), and the dependent variable being Ethical (viz., appropriate for ethics). Tables 4 and 5 shows the summary data, viz., the additive constant, and the positive coefficients for elements A1-C4.

\section{Interaction of Feelings (Silo D) with Remaining Elements among Mind-Set 1 (Ethics = Daily Living)}

We begin with the value of the additive constant across $D=0$ to $D=5$. Table 4 shows the coefficients for A1-C4. The columns are sorted by incremental value of the additive constant, the measure of basic relevance for ethics. When the specific circumstance of the situation is absent $(D=0)$, the additive constant is high, 56 . We should not be surprised. Mind-Set 1 reacts as if all behavior of whatever type is relevant for ethics.

With element D3 as the constant (hospital), the basic relevance for ethics drops 40 points, from 56 to 16 . Again, this makes sense because Mind-Set 1 focuses on the very ordinary, and D3 is an unusual, and not a daily occurrence. At the same time, elements A1-A4 reemerge as important, which is not surprising in light of the very low additive constant. With element D4 as the constant (grandchildren), the basic relevance increases from the low of 16 to the value 26 . Having grandchildren is also not a daily occurrence. The elements from silo A, daily commuter activities, no longer are drivers of ethics.

Table 4: How the interaction of elements from Question D (circumstances) with other elements drive the perception of 'ethical' (viz., involves ethics) drives responses. Data from Mind-Set 1.

\begin{tabular}{|c|c|c|c|c|c|c|}
\hline & $\begin{array}{c}\text { Top3=Ethical (Involves Ethics) } \\
\text { Mind-Set } 1\end{array}$ & $\begin{array}{c}\mathrm{D}=0 \\
\text { None }\end{array}$ & $\begin{array}{l}\mathrm{D}=3 \\
\text { You have been very sick } \\
\text { and coming from hospital }\end{array}$ & $\begin{array}{c}\mathrm{D}=4 \text { You are with } \\
\text { your young child or } \\
\text { grandchild }\end{array}$ & $\begin{array}{c}\mathrm{D}=1 \\
\text { You feel tired } \\
\text { from a long day }\end{array}$ & $\begin{array}{l}\quad \mathrm{D}=2 \\
\text { It's the weekend and you're } \\
\text { happy to see your family }\end{array}$ \\
\hline & Additive constant & 56 & 16 & 26 & 61 & 68 \\
\hline A1 & Getting on to a local bus in your neighborhood & & 26 & & & 14 \\
\hline A2 & Getting on to a shared taxi in your neighborhood & 5 & 27 & & 2 & \\
\hline A3 & Getting on to a return bus from the city to your suburb & & 29 & & & 10 \\
\hline A4 & Getting into a shared taxi from city to your suburb & 9 & 17 & & & 3 \\
\hline B1 & You give in a fixed amount that may be less and say that's all I have & & 2 & & & \\
\hline B2 & You ask the price and pay it & & & 8 & & \\
\hline B3 & You negotiate the price & & 2 & 5 & & \\
\hline B4 & You give a deliberately higher amount and play dumb & & 7 & 8 & & \\
\hline $\mathrm{C} 1$ & The money is taken, and correct change given & 6 & 12 & 6 & & \\
\hline $\mathrm{C} 2$ & The money is taken, and you pay less than you should & 12 & 13 & & & \\
\hline C3 & They forget to take your money and you say nothing & 4 & 7 & 9 & & \\
\hline $\mathrm{C} 4$ & They forget to take your money and you remind them & & 8 & 8 & 2 & \\
\hline
\end{tabular}


Table 5: How the interaction of elements from Question D (circumstances) with other elements drive the perception of 'ethical' (viz., involves ethics) drives responses. Data from Mind-Set 2.

\begin{tabular}{|c|c|c|c|c|c|c|}
\hline & $\begin{array}{l}\qquad \begin{array}{c}\text { Top3 }=\text { Involves Ethics } \\
\text { Mind-Set } 2\end{array} \\
\text { Ethics involves how you handle financial interactions (e.g., paying for a service) }\end{array}$ & $\begin{array}{c}\mathrm{D}=0 \\
\text { None }\end{array}$ & $\begin{array}{l}\quad \mathrm{D}=4 \\
\text { You are with your } \\
\text { young child or } \\
\text { grandchild }\end{array}$ & $\begin{array}{c}\mathrm{D}=3 \\
\text { You have been very } \\
\text { sick and coming } \\
\text { from hospital }\end{array}$ & $\begin{array}{c}\mathrm{D}=1 \\
\text { You feel tired } \\
\text { from a long day }\end{array}$ & $\begin{array}{l}\quad \mathrm{D}=2 \\
\text { It's the weekend } \\
\text { and you're happy } \\
\text { to see your family }\end{array}$ \\
\hline & Additive constant & 34 & 20 & 46 & 56 & 60 \\
\hline A1 & Getting on to a local bus in your neighborhood & & 3 & & & \\
\hline A2 & Getting on to a shared taxi in your neighborhood & & 9 & 4 & & \\
\hline A3 & Getting on to a return bus from the city to your suburb & & & & & \\
\hline A4 & Getting into a shared taxi from city to your suburb & & & & & \\
\hline B1 & You give in a fixed amount that may be less and say that's all I have & 14 & 20 & 12 & & 12 \\
\hline B2 & You ask the price and pay it & 11 & 24 & 31 & 12 & 27 \\
\hline B3 & You negotiate the price & 22 & 30 & 17 & 11 & 27 \\
\hline B4 & You give a deliberately higher amount and play dumb & 5 & 21 & 18 & 11 & 19 \\
\hline $\mathrm{C} 1$ & The money is taken, and correct change given & 16 & & & & \\
\hline $\mathrm{C} 2$ & The money is taken, and you pay less than you should & 27 & 11 & 2 & & \\
\hline $\mathrm{C} 3$ & They forget to take your money and you say nothing & 22 & & & & \\
\hline C4 & They forget to take your money and you remind them & 19 & 12 & & & \\
\hline
\end{tabular}

With element D1 and D2, tired and weekend, the more normal events of oneself, the additive increases. The behavior is every-day, no excuses, and the focus goes back to the absolute ordinariness of life. It is clear that for Mind-Set 1, ethics concern the everyday. What is important is the ability for Mind Genomics to discover this organizing principle with a simple study, but a study whose data structure allows this discover through studies of interactions, of scenarios produced by holding one element constant.

\section{Interaction of Feelings (Silo D) with Remaining Elements among Mind-Set2 (Ethics = Financial Behavior)}

When we look at the same analysis, this time from the point of view of data provided by Mind-Set 2, with focus on ethics involving control over money, we see a similar pattern, but the numbers differ. The absence of circumstances $(D=0)$ generates an additive constant of 34. This makes sense because for Mind-Set 2 ethics is about something under one's control, not about the world of the everyday, with everything relevant for ethics, as it is for Mind-Set 1. It is when the elements involve money, elements B1-B4, that we see the feeling that the topic is relevant for ethics. Furthermore, the coefficients are extraordinarily high and most of them are focused on elements from both Question B and Question C, the two questions dealing with money.

\section{Practical Applications - Who is in these Mindsets, and How can They be Discovered?}

We move now to the final analysis of the data, namely the discovery of who these people are, in terms of gender and age, and in terms of how they think of themselves. We finish with a way to discover these individuals in the population at large, viz., a way to begin to merge sociology, psychology, marketing, and ethics into what might be called the Mind Genomics of Ethical Inquiry, or some similar name. Table 6 shows the distribution of the 103 respondents into the two mind-sets.
Table 6: Distribution of the total panel and the two ethics mind-sets by gender, age, and self-described ethics.

\begin{tabular}{|c|c|c|c|}
\hline & Total & $\begin{array}{c}\text { MS1 } \\
\text { Ethics=Every day }\end{array}$ & $\begin{array}{c}\text { MS2 } \\
\text { Ethics=Financial }\end{array}$ \\
\hline Total & 103 & 68 & 35 \\
\hline Gender & & & \\
\hline Male & 47 & 33 & 14 \\
\hline Female & 56 & 35 & 21 \\
\hline Age & & & 8 \\
\hline Age 14-25 & 26 & 18 & 19 \\
\hline Age 26-59 & 56 & 37 & 14 \\
\hline Age 60+ & 18 & 11 & 6 \\
\hline $\begin{array}{c}\text { How do you consider yourself? } \\
\text { 1=Most of the time obey the rules } \\
\text { rigidly }\end{array}$ & 43 & 29 & 14 \\
\hline $\begin{array}{c}\text { 2=Don't complain if you get an } \\
\text { advantage and don't hurt anyone, }\end{array}$ & 20 & 14 & 1 \\
\hline 3=Pragmatic, honest but not stupid, & 34 & 20 & 5 \\
\hline \begin{tabular}{c} 
4=Not applicable \\
\hline
\end{tabular} & 6 & & \\
\hline
\end{tabular}

It is clear that the mind-sets transcend the common ways of describing oneself (gender, age), and a prima-facie way of describing one's ethics attitude during daily life.

The Personal Viewpoint Identifier (PVI) uses the created mindsets and their coefficients. The aim of the PVI is to find those elements that have the highest discriminatory power on the mind-sets. This means that it looks for the elements that are the most different among the mind-sets. In order to do so, so-called distance metrics are used which calculate the mathematical distances between the mind-sets for each element. The six most discriminatory elements are then chosen for the PVI and presented to the participants. Based on the original coefficients, the PVI can classify newly recruited participants into existing mind-sets. This way new participants do not need to complete the whole BimiLeap study but need to answer six short (binary) questions. That way assignment of new participants is fast and 


\begin{tabular}{|c|}
\hline No Specialt \\
\hline $\begin{array}{l}\text { YOU GIVE A DELIBERATELY HIGHER AMOUNT AND PLAY } \\
\text { DUMB } \\
\text { NOT A TOPIC FOR ETHICS } \\
\text { RELEVANT FOR ETHICS }\end{array}$ \\
\hline $\begin{array}{l}\text { YOU NEGOTIATE THE PRICE IF YOU CAN } \\
\text { NOTA TOPIC FOR ETHICS } \\
\text { RELEVANT FOR ETHICS }\end{array}$ \\
\hline $\begin{array}{l}\text { GETTING ON TO A LOCAL BUS IN YOUR NEIGHBORHOOD } \\
\text { NOT A TOPIC FOR ETHICS } \\
\text { RELEVANT FOR ETHICS }\end{array}$ \\
\hline $\begin{array}{l}\text { YOU ASK THE PRICE AND PAY IT } \\
\text { NOT A TOPIC FOR ETHICS } \\
\text { RELEVANT FOR ETHICS }\end{array}$ \\
\hline $\begin{array}{l}\text { YOU GIVE IN A FIXED AMOUNT THAT MAY BE LESS AND SAY } \\
\text { THAT'S ALL I HAVE } \\
\text { NOT A TOPIC FOR ETHICS } \\
\text { RELEVANT FOR ETHICS }\end{array}$ \\
\hline $\begin{array}{l}\text { GETTING ON TO A RETURN BUS FROM THE CITY TO YOUR } \\
\text { SUBURB } \\
\text { NOTA TOPIC FOR ETHICS } \\
\text { RELEVANT FOR ETHICS }\end{array}$ \\
\hline
\end{tabular}

Figure 2: Personal viewpoint identifier created using the given study. Participants are asked to answer the binary scale as soon as they can.

immediately done. The PVI is presented by Figure 2, and the mindset feedback of the PVI is presented by Figure 3. After completing the questionnaire of Figure 2 the results is immediately presented to the participant. There is room for different videos or links, which can therefore be suggested based on the mind-set memberships.

The PVI created for this specific study is available here:

https://www.pvi360.com/TypingToolPage.aspx?projectid=2292\&userid $=2008$

\section{Discussion and Conclusion}

The literature of philosophy comprises an inordinate number of papers on problems touched by the issue of ethics. Scarcely any generation can be found which did not have philosophers who focused on ethics as part of the great questions. Attempting to locate this Mind Genomics cartography in the vast ocean of ethics and philosophy would be a meaningless exercise. Rather than that, this discussion might be a good place to consider the potential of a Mind Genomics effort to quantify ethics, at least in simple, everyday matters.

\begin{tabular}{|l|}
\hline Study Name \\
COMMUTER BUS \\
YOU SEE ETHICS IN THE EVERYDAY \\
Mindset 1 Feedback \\
ETHICAL BEHAVIOR IS THE BEHAVIOR OF THE \\
ORDINARY, THE ROUTINE ACTIVITIES OF THE \\
EVERY-DAY. ETHICAL BEHAVIOR IS WHAT NORMAL \\
PEOPLE DO \\
Mindset 1 Video \\
Mindset 1 Link \\
Leave this page \\
Mindset 2 Name \\
YOU SEE ETHICS IN BUSINESS AND OTHER \\
'POWER-RELEVANT' TRANSACTIONS \\
Mindset 2 Feedback \\
ETHICAL BEHAVIOR IS AN INTERCHANGE, A \\
DECISION TO DO SOMETHING. ETHICAL BEHAVIOR \\
HAS NOTHING TO DO WITH DAILY ROUTINE \\
BEHAVIOR, BUT RATHER HAS TO DO WITH \\
VOLITIONAL BEHAVIOR, WHERE THERE ARE GAIN \\
AND LOSS INVOLVED.
\end{tabular}

Figure 3: Mind-set feedback of the personal viewpoint identifier.

It is clear from the unexpected results, viz., that people judged the vignette in terms of relevance for ethics, that we are dealing with two different aspects in this Mind Genomics cartography. The first, the goal that was not achieved, is the effort to have people judge good versus bad. That failed, perhaps because in a vignette of good versus bad the story must be clearer. There must be something which has gone wrong and is to be put aright by justice. When that is missing, the obvious right versus wrong, it may be difficult to think about the fit of the topic into the world of ethics. There is nothing to link the daily, ordinary, quotidian to what the person thinks about 'ethics.' In such a case the respondents are left to their own devices. Those belonging to Mind-Set 1 perceive the entire situation as relevant for ethics. Those belonging to Mind-Set 2 revert to issues where there can be wrongdoing, viz., the payment of money by the passenger, where it is possible to 'cheat' the bus driver. It is that situation which calls forth the relevance of ethics, at least to Mind-Set 2.

What may be the most important contribution of this paper is the method of Mind Genomics, and specifically the 'scenario analysis' to reveal the deep structure of thinking. Mind Genomics already can lay claim to being able to metricize thought. These data suggest the next level, to quantify interactions, and by so doing clarify the underlying structure of thinking, through simple experiments, done anywhere, and dealing with virtually anything where decisions by people are relevant.

\section{Acknowledgment}

AG thanks the support of the Premium Postdoctoral Researcher Program. 


\section{References}

1. Moskowitz HR, Gofman A (2007) Selling blue elephants: How to make great products that people want before they even know they want them (1st ed.). Pearson Prentice Hall.

2. Moskowitz H (2012) "Mind genomics": The experimental, inductive science of the ordinary, and its application to aspects of food and feeding. Physiology \& Behavior 107: 606-613. [crossref]

3. Moskowitz HR, Gofman A, Beckley J, Ashman, H (2006) Founding a new science: Mind genomics. Journal of Sensory Studies 21: 266-307.

4. Milutinovic V, Salom J (2016) Mind genomics. a guide to data-driven marketing strategy. Springer International Publishing.

5. Gustafsson A, Herrmann A, Huber F (2001) conjoint measurement: Methods and applications. Springer.

6. Harizi A, Trebicka B, Tartaraj A (2020) A mind genomics cartography of shopping behavior for food products during the covid -19 pandemic. European Journal of Medicine and Natural Scinces Articles 4: 25-33.

7. Moskowitz H, Wren J, Papajorgji P (2020) Mind Genomics and the Law. LAP LAMBERT Academic Publishing
8. Gino F (2015) Understanding ordinary unethical behavior: Why people who value morality act immorally. Current Opinion in Behavioral Sciences 3: 107-111.

9. Rawls J (1951) Outline of a decision procedure for ethics. The Philosophical Review 60: 177-197.

10. Nguyen NT, Basuray MT, Smith WP, Kopka D, McCulloh DN (2008) Ethics perception: Does teaching make a difference? Journal of Education for Business 84: 66-75.

11. Creyer HE (1997) The influence of firm behavior on purchase intention: do consumers really care about business ethics? Journal of Consumer Marketing 14: 421-432.

12. Singh P, Doti R. Lugo JE, Faubert J, Rawat S, et al, (2018) DNA as an electromagnetic fractal cavity resonator: Its universal sensing and fractal antenna behavior bt - soft computing: theories and applications. In M. Pant K, Ray TK, Sharma S, Rawat A, Bandyopadhyay (Eds.), Soft Computing: Theories and Applications. Advances in Intelligent Systems and Computing.

13. Ryan TP, Morgan JP (2007) Modern experimental design. Journal of Statistical Theory and Practice 1: 501-506.

14. Gofman A, Moskowitz H (2010) isomorphic permuted experimental designs and their application in conjoint analysis. Journal of Sensory Studies 25: 127-145.

15. Dubes R, Jain AK (1980) clustering methodologies in exploratory data analysis. Advances in Computers 19: 113-228.

\section{Citation:}

Moskowitz H, Kover A, Deitel P, Belger H, Vuk Savicevich K, et al. (2021) Paying Fare and Playing Fair on a Commuter Bus: A Mind Genomics Cartography of Topics Appropriate for Ethics. Psychol J Res Open Volume 3(2): 1-9. 